\title{
BIODIGESTÃO ANAERÓBIA DA VINHAÇA PARA PRODUÇÃO DO BIOGÁS
}

\author{
M. V. BOSCHIERO ${ }^{1}$, C. F. MARTINS ${ }^{1}$, V. R. S. $\operatorname{ALVES}^{1}$ e P. R. F. ROSA ${ }^{1}$ \\ ${ }^{1}$ Universidade Federal de São Carlos, Departamento de Engenharia Química \\ E-mail para contato: marcelovboschiero@gmail.com
}

\begin{abstract}
RESUMO - O objetivo deste trabalho foi estudar o potencial da vinhaça para a produção de biogás, através de um planejamento de experimentos. A vinhaça foi doada pela Usina Ipiranga, Descalvado- SP. Um planejamento fatorial do tipo composto central a dois níveis foi realizado, com dois fatores principais: concentração de vinhaça e $\mathrm{pH}$, cuja a região dos valores foi escolhida de forma a obter um biogás rico em hidrogênio, segundo a literatura. A resposta do planejamento foi a produção de biogás em cada caso. Com os resultados obtidos verificou-se que todos os fatores são significativos, sendo que valores baixos de pH não favorecem a produção de biogás ao passo que valores elevados de concentração de vinhaça favorecem sua produção. Estes valores de concentração indicam possibilidade de se utilizar vinhaça in natura como substrato para a produção de biogás, sendo uma vantagem tecnológica, e operacional.
\end{abstract}

\section{INTRODUÇÃO}

No Brasil, devido às constantes crises econômicas e decorrentes flutuações no preço do petróleo, criou-se, no ano de 1975, o Proálcool (Programa Nacional do Álcool), visando promover a produção do biocombustível, a partir da cana de açúcar, aliado ao já consolidado setor açucareiro. No entanto, a estabilização do preço do petróleo (1980) bem como a valorização do preço do açúcar (1990), forçou o governo a promulgar a Lei nº.723, tornando obrigatória uma porcentagem de etanol anidro na gasolina, valor que está atualmente em $27 \%$ na mistura. Esse aumento do volume de etanol produzido gerou, consequentemente, um aumento proporcional no volume de vinhaça.

A vinhaça é o produto de fundo da coluna de esgotamento, que é a primeira do conjunto de colunas de destilação alcoólica do vinho gerado em usinas ou em destilarias autônomas. De acordo com Pinto (1999), a vinhaça trata-se de uma suspensão de sólidos orgânicos e minerais, com elevada DQO (Demanda Química de Oxigênio) e DBO (Demando Bioquímica de Oxigênio), com grande potencial poluidor. Vazoller (1997) relacionou os elevados valores de matéria orgânica da vinhaça à presença de etanol, açúcares, glicerol e alguns ácidos orgânicos. Atualmente é utilizada como fonte de potássio em adubação em um processo conhecido como fertirrigação (MACHADO et al., 2009)

Uma tecnologia alternativa para reduzir o potencial poluidor da vinhaça quanto à matéria orgânica é a digestão anaeróbica desse substrato, gerando produtos finais de valor econômico, como o gás metano combustível. Além de garantir um novo atrativo econômico, esse tratamento biológico reduz a carga orgânica presente na vinhaça, dando maior segurança 
na sua utilização como fertilizante. É importante ressaltar que, mesmo após a digestão, a vinhaça apresenta quantidades consideráveis de nutrientes como o potássio (MADEJÓN et al., 2001).

Para entender melhor a complexidade do processo anaeróbio, a Figura 1 apresenta a rota metabólica das culturas microbianas que agem de forma catalítica no processo que, através de uma série de etapas, convertem os substratos alimentados em vários metabólitos e componentes gasosos. O processo de digestão anaeróbia permite converter matéria orgânica complexa em gás carbônico e metano. É desenvolvida por uma sequência de ações e uma variedade de bactérias e archaeas, no qual se podem distinguir as fases: hidrólise, acidogênese, acetogênese e metanogênese, conforme mostra a Figura 1.

Figura 1 - Rotas metabólicas da biodigestão anaeróbia

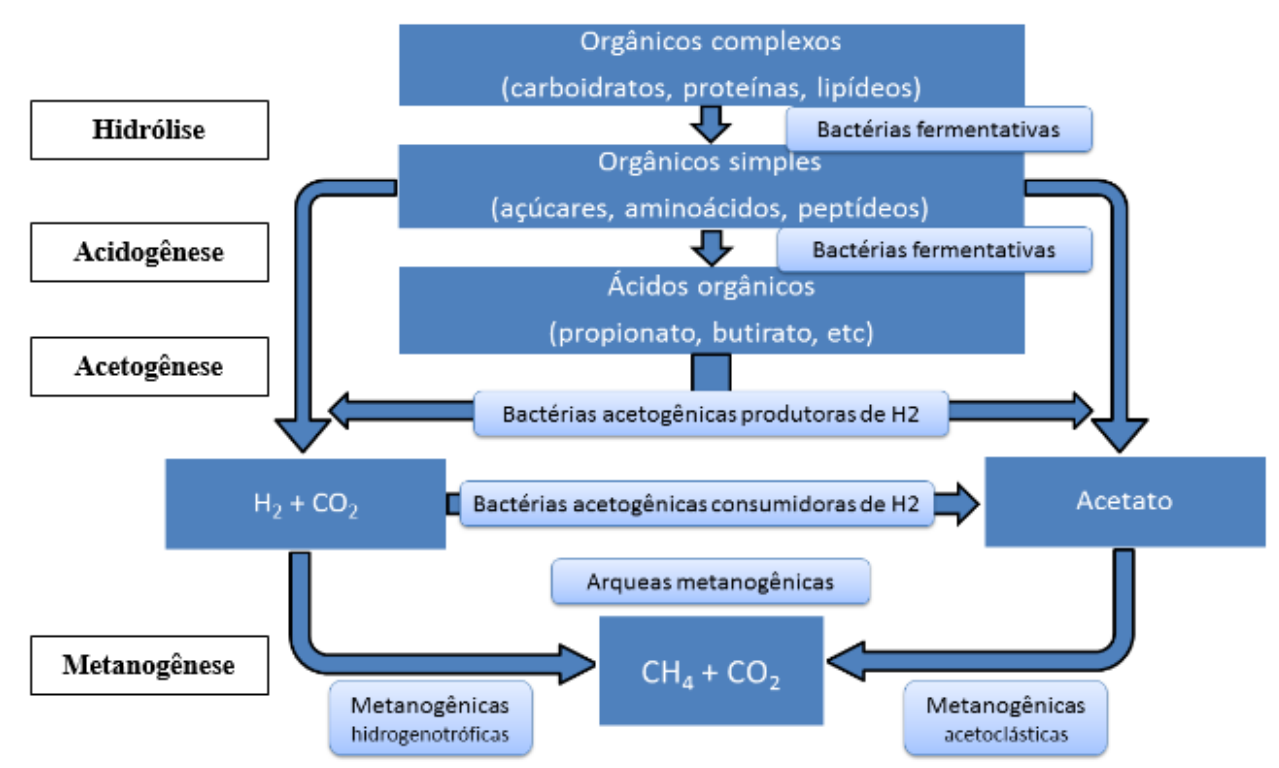

Fonte: Chernicharo, 1997

A questão é como atingir condições ideais de produção de biogás, mantendo reduzidos os custos de tratamento, considerando os parâmetros operacionais como o pH e concentração de substrato. Assim, este trabalho teve como objetivo analisar a viabilidade da produção de biogás a partir da biodigestão anaeróbia da vinhaça. Além disso, a influencia do $\mathrm{pH}$ e da concentração de substrato (DQO) no volume de produto obtido também foi avaliado.

\section{MATERIAIS E MÉTODOS}

\section{1 Água residuária e Inóculo utilizados para a produção de biogás}

A vinhaça utilizada nos experimentos foi proveniente da Usina Ipiranga, situada na cidade de Descalvado, interior do estado de São Paulo. Foi realizado o armazenamento da vinhaça em freezer $\left(-5^{\circ} \mathrm{C}\right)$. O elevado conteúdo orgânico contido nesta água residuária, de cerca de $25.000 \mathrm{mg}$ DQO.L $\mathrm{L}^{-1}$, foi diluído com valores entre 1.890 a $23.110 \mathrm{mg}$ DQO.L ${ }^{-1}$. 
A fonte de inóculo utilizada durante os ensaios realizados foi proveniente da estação de tratamento de esgoto da cidade de São Carlos, interior do estado de São Paulo. Este lodo foi submetido a um pré-tratamento térmico, conforme a metodologia adaptada proposta por Kim et al. (2006).

\subsection{Planejamento Experimental}

Foi aplicado um planejamento fatorial do tipo composto central rotacional (PCCR) a dois níveis, com duas variáveis, acrescido de três réplicas no ponto central, $2^{2}$ ensaios para a investigação de um modelo linear e ainda quatro experimentos nos pontos axiais $(\alpha)$, totalizando 11 experimentos (BOX e HUNTER, 1987). O planejamento de experimentos é uma alternativa para minimizar o número de experimentos e, ainda assim, estudar a influência de cada fator e de suas interações. Para a realização dos experimentos, foi avaliado o efeito do pH e concentração de substrato como sendo os fatores. Os níveis codificados e não codificados estão apresentados na Tabela 1.

Tabela 1 - Matriz do planejamento composto central rotacional.

\begin{tabular}{|c|c|c|c|c|c|}
\hline Níveis & $-1,4142$ & -1 & 0 & +1 & $+1,4142$ \\
\hline $\mathrm{pH}$ & 5,79 & 6,0 & 6,5 & 7,0 & 7,21 \\
\hline Cs $\left(\mathrm{mgDQO} . \mathrm{L}^{-1}\right)$ & 1.890 & 5.000 & 12.500 & 20.000 & 23.110 \\
\hline
\end{tabular}

2.2.1Ensaios Preliminares: Foram realizados ensaios preliminares, de modo a estudar e estabelecer as melhores condições para produção e medição do biogás nos frascos de Duran de $250 \mathrm{~mL}$. Para tanto, foram utilizados os valores dos pontos centrais de $\mathrm{pH}$ e concentração de substrato (pH e concentração de 6.500 e 12.500 mgDQO.L ${ }^{-1}$, respectivamente). Foram avaliados diferentes headspace (30-10\%) e porcentagem de lodo (10 e 20\%). Ao final desses ensaios, escolheu-se as seguintes condições de experimento: 10\% de headspace; $20 \%$ (em volume) de lodo. O tempo de fermentação de $48 \mathrm{~h}$ foi baseado em estudos anteriores (SANTOS 2014). O volume de biogás produzido foi medido com auxílio de um manômetro de tubo em U preenchido com mercúrio e com uma das extremidades abertas, onde uma agulha fina - conectada ao manômetro por um tubo em sua outra extremidade - era injetada na tampa frasco de Duran e o deslocamento de mercúrio causado pelo gás era medido, assim por uma balanço estático de pressões era possível quantificar o biogás produzido.

2.2.2 Ensaios em Batelada: Os ensaios em batelada foram realizados utilizando as conclusões obtidas através dos ensaios preliminares, variando-se os níveis de cada fator. Utilizando a matriz do Planejamento Composto Central Rotacional, exibida na Tabela 1 acima, foram definidas as combinações de $\mathrm{pH}$ e concentração de substrato utilizadas em cada um dos ensaios, os quais foram realizados em triplicata.

$\mathrm{O}$ ajuste do $\mathrm{pH}$ inicial foi realizado pela adição de bicarbonato de sódio P.A, com auxílio de um pHmêtro. As condições anaeróbias foram mantidas a partir do uso de nitrogênio.

\subsection{Métodos analíticos}


As análises de DQO e pH foram feitas de acordo com o APHA: Standard Methods for the Examination of Water and Wastewater (2012).

\section{RESULTADOS E DISCUSSÃO}

\subsection{Produtividade de Biogás}

De acordo com a matriz do planejamento de experimentos, que rege os valores de $\mathrm{pH}$ e de concentração do substrato $\left(\mathrm{C}_{\mathrm{s}}\right)$, foram obtidos resultados apresentados na Tabela 2 para a produção de biogás. No melhor ponto, experimento 4 , que tinha uma das condições mais altas de $\mathrm{pH}$ e concentração, gerou $0,75 \mathrm{~mL} / \mathrm{h}$ de biogás.

Diante do exposto é possível notar, de forma preliminar, que valores baixos de $\mathrm{pH}$ não favorecem a produção de biogás ao passo que valores elevados de Cs favorecem sua produção. No entanto, somente mediante tratamento estatístico será possível realizar uma análise mais precisa.

Tabela 2 - Valores de biogás total produzido (em $\mathrm{mL}$ ) e a produtividade ao longo das 48h de fermentação.

\begin{tabular}{|c|c|c|c|c|}
\hline Ensaio & $\mathrm{pH}$ & $\mathrm{Cs}\left[\mathrm{mgDQO} . \mathrm{L}^{-1}\right]$ & $\mathrm{V}_{\text {biogás }}[\mathrm{mL}]$ & Produtividade $[\mathrm{mL} / \mathrm{h}]$ \\
\hline 1 & $-1(6)$ & $-1(5.000)$ & 2,572 & 0,0536 \\
\hline 2 & $+1(7)$ & $-1(5.000)$ & 3,807 & 0,0793 \\
\hline 3 & $-1(6)$ & $+1(20.000)$ & 8,697 & 0,1812 \\
\hline 4 & $+1(7)$ & $+1(20.000)$ & 35,959 & 0,7491 \\
\hline 5 & $-1,41(5,79)$ & $0(12.500)$ & 15,557 & 0,3241 \\
\hline 6 & $+1,41(7,21)$ & $0(12.500)$ & 18,197 & 0,3791 \\
\hline 7 & $0(6,5)$ & $-1,41(1.890)$ & 0,519 & 0,0108 \\
\hline 8 & $0(6,5)$ & $+1,41(23.110)$ & 21,397 & 0,4458 \\
\hline 9 & $0(6,5)$ & $0(12.500)$ & 21,984 & 0,4580 \\
\hline 10 & $0(6,5)$ & $0(12.500)$ & 25,094 & 0,5228 \\
\hline 11 & $0(6,5)$ & $0(12.500)$ & 25,966 & 0,5410 \\
\hline
\end{tabular}

\subsection{Análise Estatística}

Devido às características do planejamento de experimentos e posterior tratamento estatístico, é possível, por meio do software Statistica, verificar o quão relevante são os fatores e suas interações para a produção do biogás. Para isso, fixou-se o intervalo de confiança em $90 \%$ conforme a literatura recomenda para o planejamento de bioprocessos (RODRIGUES e IEMMA, 2009)

Sendo assim, é possível construir um modelo de segunda ordem para descrever o fenômeno (nas condições estudadas), com base nos coeficientes obtidos para cada fator, que 
prevê o volume de biogás produzido (em $\mathrm{mL}$ ), conforme a Equação 1, que teve um coeficiente de determinação $\mathrm{R}^{2}=0,931$.

$$
V=23,84-3,68 p H^{2}-6,86 C s^{2}+4,06 p H+8,60 C s+6,67 p H . C s
$$

Baseado no modelo de correlação entre fatores e variáveis resposta, pode-se construir a superfície de resposta para avaliar visualmente o modelo obtido bem como as curvas de nível, apresentadas na Figura 2. As regiões em verde apresentam baixa produção de biogás, enquanto as áreas em vermelho e vinho apresentam alta produção.

Figura 2 - Relações entre os fatores avaliados na produção de biogás.
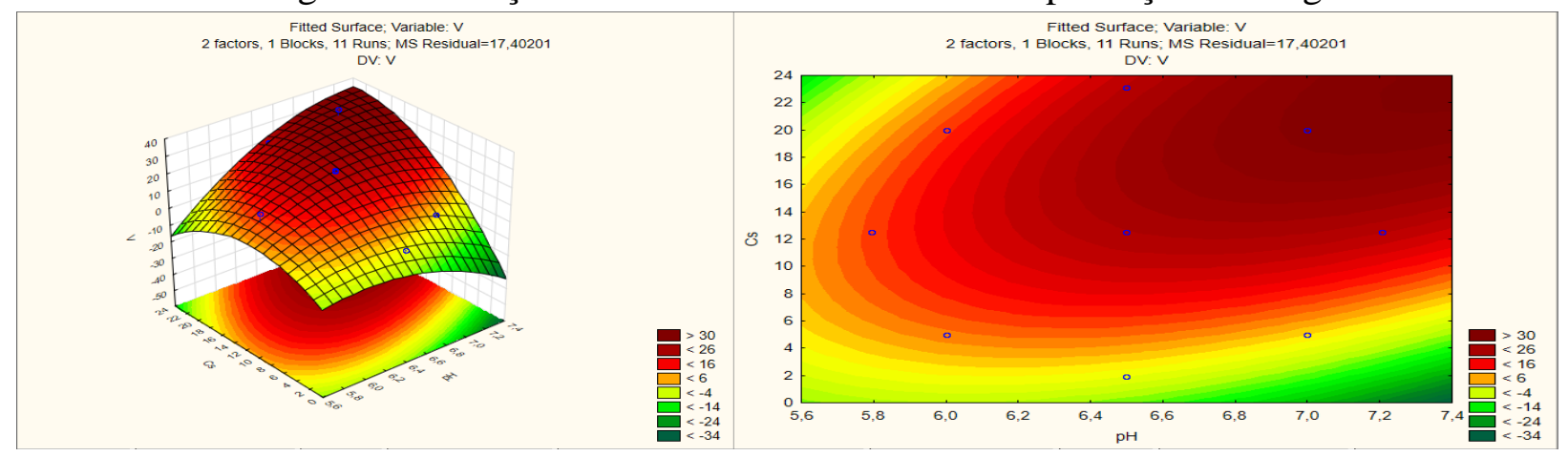

Legenda: (a) primeira figura: superfície resposta incluindo os fatores e a variável resposta (b) segunda figura: superfície resposta em curvas de nível

Analisando a superfície de resposta obtida, figura 2-a fica claro que, devido ao seu formato de "rampa", o volume de biogás produzido aumenta conforme os valores dos fatores (pH e Cs) também aumentam. Porém, fica difícil visualizar, nesse gráfico, a região exata de valores de $\mathrm{pH}$ e Cs que maximizaram a produção de biogás. Para isso, analisam-se, então, as curvas de nível de resposta, figura 2-b, para determinar a faixa de valores ótimo. O esquema de cores segue o mesmo padrão da superfície de resposta.

A partir da região em vermelho escuro da Curva de Nível da Figura 2, pode-se concluir que a região, prevista pelo modelo, na qual ocorre a máxima produção de biogás, está localizada em valores de $\mathrm{pH}$ entre 7,2 e 7,4 e valores de concentração de substrato entre 22.000 e $24.000 \mathrm{mgDQO} \mathrm{L}^{-1}$. O simples fato de fornecer mais nutriente para os microrganismos realizarem a digestão ajuda a explicar a faixa elevada de valores de substrato. E ainda, devido à característica desse bioprocesso em tender a acidificar o meio em que se encontra, os valores de $\mathrm{pH}$ inicial entre 7,2 e 7,4 favorecem uma boa produção de biogás uma vez que retardam a rápida acidificação do meio

Analisando as Figura 2, pode-se inferir, também, que valores elevados de substrato indicam possibilidade de utilizar-se vinhaça in natura para emprego em biodigestão anaeróbia. Seria uma vantagem tecnológica e operacional o fato de utilizar esse subproduto na mesma forma em que é produzido, bastando apenas corrigir seu $\mathrm{pH}$.

\section{CONCLUSÃO}


A produção de biogás durante a biodigestão indica viabilidade técnica para essa alternativa de redução do potencial poluidor da vinhaça.

Embora a região ótima encontrada esteja no limite superior do intervalo testado, os resultados indicam que vinhaça in natura pode ser empregada. Mas, para isso, um novo planejamento experimental deve ser feito para que abranja faixas de substrato superiores, com valores de $\mathrm{pH}$ previamente otimizados nesse trabalho.

\section{REFERÊNCIAS}

APHA, AWWA, WPCF. Standard methods for the examination of water and wastewater. 22 th. Washington, 2012.

BOX, G.E.P.; HUNTER, W.G.; HUNTER, J.S. Statistic for experimenters: an introduction to design, data analysis and model building. New York: Wiley, 1978.

CHERNICHARO, C.A.L. Reatores anaeróbios. 2ed. Belo Horizonte: Departamento de Engenharia Sanitária e Ambiental UFMG, 1997. 380p. 5v. (Princípios do Tratamento Biológico de Águas Residuárias).

KIM, D.-H., HAN, S.-K., KIM, S.-H., SHIN, H.-S. Effect of gas sparging on continuous fermentative hydrogen production. International Journal of Hydrogen Energy, 31(15), 2158-2169, 2006.

MACHADO, O. J.; FREIRE, F. B. Tratamento de vinhaça em reator anaeróbio de fluxo ascendente e manta de lodo (UASB). Olam: Ciência \& Tecnologia, Rio Claro, n. 2, p. 170, 2009. Número especial. Disponível em: <http://www.cau.uem.br/cau/images/stories/2837-12792-1-PB.pdf >. Acesso em: 26 jun 2016.

MADEJÓN E, LÓPEZ R, MURILLO JM, CABRERA F. Agricultural use of three (sugarbeet) vinasse composts: effect on crops and chemical properties of a Cambisol 64 soil in the Guadalquivir river valley (SW Spain). Agric Ecosyst Environ, v. 84, p. 55$65,2001$.

PINTO, C.P. Tecnologia de biodigestão anaeróbia de vinhaça e de desenvolvimento sustentável. 1999. 147 f. Dissertação (Mestrado em Planejamento de Sistemas Energéticos) - Faculdade de Engenharia Mecânica, Universidade Estadual de Campinas, Campinas, 1999.

RODRIGUES, M. I; IEMMA, A. F. Planejamento de Experimentos \& Otimização de Processos. $2^{\text {a }}$ Ed. Campinas: Cárita, 2009. 358 p.

SANTOS, S. C. Produção de hidrogênio em reator anaeróbio de leito fluidificado termofílico com vinhaça como substrato orgânico. São Carlos. EESC, USP. 2014.

VAZOLLER, R. F. Microbial aspects of thermophilic anaerobic biodigestion of vinasse. In: Proceedings of ISME, v. 7, p. 527-532, 1997. 